\title{
Paranoia Das Massas Da Era Digital - Os Softidiots E A BIGBROTHERIZAÇÃo
}

\section{Antonio Quinet1}

\section{RESUMO}

Este trabalho é um ensaio sobre a estrutura do estado paranoico na era digital a partir dos conceitos de sociedade escópica (Quinet), objeto (a) olhar (Lacan), e psicologia das massas (Freud). A pulsão escópica, com o gozo de ver-ser-visto, dá a base ao modelo do panóptico de Bentham da sociedade disciplinar de vigilância monitorizada como desenvolveu Michel Foucault. Esse modelo foi levado a seu zênite na era digital. Estudamos sua utilização na política com a estratégia da "bigbrotherização" que tem por objetivo a manipulação dessubjetivante dos indivíduos e a formação de "softidiots". Eis a tendência que encontramos particularmente na atual conjuntura de muitos países incluindo, de forma diferente, o Brasil e a China.

Palavras-Chaves: Paranoia; Panóptico; Bigbrotherização; Psicanálise; Pulsão Escópica

1 Médico, psiquiatra, psicanalista, doutor em Filosofia e dramaturgo. É Analista Membro da Escola (AME) de Psicanálise dos Fóruns do Campo Lacaniano, Professor Adjunto do Mestrado e Doutorado de Psicanálise, Saúde e Sociedade da UVA. Fundou a Cia. Inconsciente em Cena da qual é diretor. É pesquisador da FAPERJ (pesquisa Hilda \& Freud - collected words). É Professor convidado do Instituto de Psiquiatria da UFRJ. 
Nossa sociedade transformou-se em uma "sociedade escópica" na qual o olhar é prevalente, onde o visto e ser visto se tornou uma prerrogativa, não só pela promoção do imperativo de exibir-se e do espírito selfie que possui e baixa nos corpos humanos, como também pela vigilância a que somos permanentemente submetidos por câmeras, GPS, localizadores, etc. promovendo uma paranoização de massa.

Em vários países do mundo o Estado utiliza o dispositivo de paranoização para controlar, vigiar e punir os cidadãos. Assim a sociedade disciplinar como um todo, como apontou Michel Foucault em 'Vigiar e Punir', vira um grande panóptico, descrito por Jeremy Benthan, como a forma arquitetônica constituída por um grande torre num pátio aberto rodeada a poucos metros por uma construção redonda com celas abertas e transparentes de tal modo que um vigia na torre central possa ver (sem ser visto) tudo o que ocorre nas celas de toda a estrutura circular, onde cada prisioneiro, ou louco em cada cela é totalmente transparente. Essa forma arquitetônica, que foi (e em muitos lugares ainda é) utilizada para prisões e manicômios foi dando o lugar para as câmeras nas ruas, nas casas, nos escritórios, fábricas, etc. e com a revolução digital e o advento da internet passou-se a visualizar todos os dados, gostos, percursos, preferências sexuais, projetos de cada usuário. A sociedade escópica ganhou como aliado o panoptismo digital. E assim é mantido o mesmo funcionamento da forma arquitetônica do panóptico: a transparência do usuário e a invisibilidade do vigia.

No estado paranoico, a voz que sonoriza o olhar se torna presente como êxtimo (um íntimo externo) encarnado pelo líder. Essa é a política do mais-de-gozar utilizando a tecnologia de ponta da internet. Os dados de todos os que estão na internet são coletados e utilizados para o controle de estado, como veremos mais adiante, já em ação na China. Eis o que estudaremos mais profundamente neste texto.

\section{A SOCIEDADE Escópica}

Nossa sociedade atual pode denominar-se Sociedade Escópica, onde o olhar é prevalente. É uma expressão que proponho a partir da psicanálise - tema que desenvolvo na minha tese de doutorado em filosofia sobre a pulsão escópica, o verser-visto na clínica e na sociedade - que é a conjunção da sociedade do espetáculo descrita por Guy Debord e da sociedade disciplinar descrita por Michel Foucault. 
É o olhar, excluído da simbolização efetuada pela cultura sobre a natureza, que retorna sobre a civilização, trazendo o gozo do espetáculo e o imperativo do supereu de um empuxo-a-gozar escópico: um comando de dar-a-ver, seja de mostrar-se inocente e bom cidadão, seja de tornar-se visível. De toda forma, na sociedade escópica, para existir, é preciso ser visto pelo Outro. E assim se instaura a renovação do velho cogito religioso: o Outro me vê logo eu existo.

A expansão do fenômeno religião é hoje também um fato correlativo ao desenvolvimento da sociedade escópica com seu cogito do olhar do Outro. A religião é um sistema de representação que, à semelhança do delírio, constitui um enquadramento do olhar, fazendo-o assim existir. Esse sistema encontra em Deus seu Ser-supremo-em-olhar em duas versões: do bem e do mal. Do bem, trata-se do Deus da religião; do mal, o Ser-supremo-em-maldade de Sade, descrito em "A filosofia na alcova".

\section{O SHOW DAS IMAGENS}

Guy Debord diagnosticou nossa sociedade: é uma sociedade do espetáculo. Nossa sociedade de business é efetivamente uma sociedade de show e segundo o mote americano: there is no business like show-business.

Lá onde o mundo real se transforma em imagens, as imagens se tornam mais reais para o gozo do espectador. O show da guerra filmada, chocante em Apocalipse Now, está hoje banalizado. Orgias de sangue, bacanais de membros despedaçados invadem nosso cotidiano com os "aqui e agora" das atrocidades live. São imagens do espetáculo que trazem o gozo do olhar que acorda o espectador com um horror excitante. A pulsão escópica se satisfaz no imaginário por sua face silenciosa e trágica, retraçando imagens que permanecem, que não se apagam. São imagens indeléveis inscritas na pulsão de morte, coladas ao olhar letal do real libidinal.

O espetáculo da imagem tem seu lado belo, faz suspirar o sujeito do desejo devido à sua pulsação e brilho, que encobre a falta que lhe é constitutiva. Mas o espetáculo é também sede do mal-estar na cultura ao presentificar o supereu com suas imagens impregnadas pelo real impossível de suportar que provocam 0 sentimento de culpa no sujeito. São imagens que olham para o espectador, que causam desejo e horror. 
Essas imagens também chegam a nós como imperativos de ideais a serem seguidos, modelos de identificação que são fabricados pela publicidade e pelo esporte, no qual o apelo à identificação é tanto mais imaginário por fazer um apelo direto ao corpo: seja futebol, vôlei, ou basquete, onde não só a imagem do corpo está presente, mas o desempenho. O poder da imagem - devido a seu poder de captação, fascinação, captura - faz o espectador identificar-se com o desportista, e achar que, quando seu time ganha, ele também está de alguma forma ganhando. O poder da imagem faz o espectador acreditar-se um vencedor, quando na verdade está apenas sentado em sua casa bebendo uma cerveja diante de uma telinha.

A sociedade escópica, impulsionada pelo discurso do capitalismo, se apropria disso para transformar o exibicionismo próprio do sujeito em imperativo de publicidade, ordenando ao sujeito fazer de tudo para roubar a cena. E assim, conquistar um lugar ao sol. A sociedade escópica reatualiza a ilusão de que o sol brilha para todos ao acenar com a possibilidade de qualquer um pode ser uma celebridade.

Na sociedade escópica, o olhar, dejeto da civilização, mais-de-gozar, é elevado ao status de mestre/senhor, ou melhor, é utilizado pelo mestre/senhor fazendo fundir assim o $S_{1}$ da lei com olhar vigilante e exigente do Grande Diretor. O propósito dessa sociedade parece ser o de fazer de nossas vidas um Show de Truman (1998), filme de Peter Weir. Truman Burbank foi adotado ao nascer por uma grande rede de comunicação e tem todos os passos de sua vida filmados durante 24 horas. Esse filme mostra que, mais do que a ficção, a realidade nua e crua é muito mais espetacular. Os programas de reality show mostram isso transmitindo sua ideologia de merchandising e imperativo de mostração para fazer existir um Outro do olhar, panóptico, onividente. Como veremos mais adiante, a sociedade escópica foi acrescida da tecnologia digital ampliando o controle, a vigilância e a transparência.

\section{O PANOPTISMO DisciplinAR}

Na sociedade escópica, o paradoxo do gozo faz com que cada homem queira fazer de seu próximo um ator e um espectador de um espetáculo obsceno e feroz à altura do supereu que vigia e pune. É o que podemos depreender do que Foucault chamou de "sociedade disciplinar" baseada da estrutura panóptica descrita por Jeremy Bentham. 
Diz-se que "a justiça é cega", mas ela não deixa de ver. O supereu é o lugar desse paradoxo da lei: é uma lei que não tem objeto, como nos ensina Kant, mas não deixa de tê-lo, como nos mostrou Lacan. Esse objeto é o objeto a, que se apresenta ao sujeito como o olhar da vigilância da lei, e como a voz da instância crítica. Assim o olhar representa o supereu do sujeito, a instância de vigilância permanente. A lei como máxima pura $\left(\mathrm{S}_{1}\right)$ e a lei como instância de vigilância e crítica (a) são as duas faces do que o sujeito sofre de sua instância moral. Sua conjunção $\left(S_{1} / a\right)$ faz do Outro o Um que o vigia, julga e pune. O objeto presente na lei se exprime na clínica pelo delírio de observação e na civilização pela estrutura "panóptica" da sociedade escópica em que o olhar do Outro faz a lei.

Essa estrutura do olhar como objeto a está presente no Panóptico de Bentham, uma figura arquitetônica usada no final do século XVIII para vigiar os prisioneiros, cujo modelo serviu para loucos, doentes, estudantes e operários. Trata-se de uma construção composta de uma torre central e de um edifício que a circunda. $O$ vigilante permanece na torre sem que possa ser visto enquanto os prisioneiros estão no edifício circular em celas transparentes, banhados pela luz, para que a visibilidade seja total. Na verdade, o vigilante nem precisa estar lá, basta uma veneziana ou um vidro escuro para fazer existir o olhar. O panóptico dissocia o par ver-ser-visto, e faz do sujeito não um ser que vê, mas um ser visto que está o tempo todo sob o foco do olhar do Outro, engaiolado na pirâmide visual do Outro. Com esse artifício, o panóptico torna o olhar ao mesmo tempo totalizador (e totalitário) e particularizado para cada um. O olhar é para todos, universal, e para cada um, singular.

Publicado em 1791, o panóptico de Bentham foi redescoberto por Michel Foucault ao estudar as origens da clínica médica. Arquitetura também encontrada nos projetos de reforma penitenciária e da Escola Militar de Paris de 1751. O panóptico foi a solução em termos da tecnologia do poder para os problemas de controle e vigilância da parte dos penalistas, médicos, educadores e industriais, que a partir dele construíram prisões, hospitais, escolas e fábricas.

Com o panóptico, Bentham dissolve o quiasma próprio do campo visual que é o entrelaçamento entre o ver e o ser visto, próprio da pulsão escópica, propondo um Olho central que torna os sujeitos transparentes, sem anteparo tela, quadro ou espelho protetor. Seu sistema se assemelha ao que encontramos na clínica do delírio de observação frequente na paranoia. É um sistema que podemos qualificar de 
paranoico na medida em que localiza o gozo escópico no Outro do poder fazendo crer que o Outro efetivamente pode ver tudo o que o sujeito faz e até mesmo pensa. Coloca assim em prática o "olho domiciliar" do Big Brother presente na casa de todos na ficção de George Orwell, 1984.

Michel Foucault mostrou em "Vigiar e punir" que o panóptico é o modelo de nossa sociedade disciplinar, a qual, para controlar os indivíduos, deve torná-los visíveis em todos os momentos, enquanto seu Olho está invisível para que reine o objeto olhar. Todos são manchas no quadro da norma - presentificação do mais-deolhar.

Trata-se, com efeito, de um modelo cuja estrutura nos é dada pela pulsão escópica e pelo olhar como objeto a. O panóptico nada mais faz senão dar uma estrutura de cimento armado àquilo que a psicanálise desvela como olhar do supereu, correlato da mancha que o sujeito faz na sociedade disciplinar, em que o olhar está por todas as partes como expressão do mal-estar na civilização. Com o panóptico, Bentham, avant da lettre (freudienne), utiliza a instância do supereu na tentativa de promover a interiorização do olhar para controlar os atos e até mesmo o pensamento dos que ele vigia. Esse olhar do supereu faz existir o Outro como receptador de gozo, constituindo o Outro do poder com seu olhar fuzilante, trazendo-lhe uma existência que inexiste e uma vigilância efetiva de controle social. Torna assim o sujeito transparente submetido ao comando de dar-se a ver.

\section{A TRANSPARÊNCIA}

Para Bentham, a questão da visibilidade se organiza em torno de um único olhar dominador e vigilante como técnica do poder e do controle, fazendo a todos seres visíveis e transparente. Tem olhar de Um, aquele que ocupa literal ou simbolicamente a torre central, que faz a função de Lei representando os olhos do poder, que vê sem ser visto, e todos os outros são vistos por ele, transparentes. Os prisioneiros do panóptico não se vêem uns aos outros, há barreiras entre suas celas. Como cada um hoje em dia na era digital, pode ser visto e filmado por sua câmera do notebook ou do celular sem saber na intimidade de sua vida privada, sozinho sem contato com mais ninguém.

A transparência como ideal também invade a vida privada de pessoas (ditas) públicas, como artistas, políticos, "celebridades" de quem, por se darem a ver em 
público, é exigida transparência total como imperativo da sociedade escópica. O sujeito ávido de curiosidade do que está escondido é também o sujeito ávido por publicidade - tudo em nome do ideal da transparência que se torna imperativo. $O$ mesmo sujeito que quer ser visto sob os holofotes (da fama e do prestígio) exige a transparência de seus próximos. E perde grande parte de seu tempo espionando os colegas e amigos, a vida de artistas, dos políticos no Instagran e Facebook, etc.

A sociedade escópica com seu imperativo de gozo $\left(S_{1}\right)$ faz cada um sentir-se vigiado e vigiar o outro, e também cada um querer publicidade - "seja uma celebridade!" - e invadir a privacidade do outro, fazer da intimidade, exterioridade, tornar público o privado. E ter seu que será momento de fama e o maior número de seguidores nas redes sociais. O imperativo do mais-de-olhar, com sua topologia de extimidade, traz à sociedade sua estrutura moebiana embaralhando as esferas do que é do sujeito e do outro. Estende assim o propósito do panóptico em que impera o olhar que vigia e, como diz Foucault, "cada um, sentindo-o pesar sobre si, terminará por interiorizá-lo ao ponto de observar-se a si mesmo; cada um assim exercerá essa vigilância sobre e contra ele mesmo". Esta estrutura desvelada no delírio de observação é arquitetada e concretizada pela sociedade escópica. Ela é a base da razão paranoica - hiper ampliada na era digital.

Se Bentham formulou a técnica do olho do Poder, foi Freud quem teorizou a instância de vigilância e crítica - o supereu - que existe dentro do sujeito e Lacan quem nomeou o objeto pulsional aí em gozo. É o mais-de-olhar, como função do supereu, que permite a existência e a efetivação concreta do panóptico.

A transparência é o grande inimigo da política, como diz Rancière, a qual é "ameaçada de morte quando se faz menção de submetê-la ao reino midiático da visibilidade e da publicidade integrais". Podemos dizer que o mesmo se aplica para a justiça. Segundo o criminalista italiano Antonio Cristiani (Universidade de Pisa), "o segredo é uma garantia para a Justiça e para o cidadão" - garantia estabelecida inclusive pelo código processual penal italiano (artigo 329).

Atualmente a evolução tecnológica prescinde efetivamente do cimento armado para fazer existir o panoptismo, ao instituir a arma do virtual em suas formas de televigilância, algemas eletrônicas, escuta ambiental, e - depois do que Snowden revelou ao mundo em 2013 - todo o sistema eletrônico e digital é usado para vigiar, influenciar, fazer comprar e fazer votar determinando gostos e desgostos. 
A sociedade escópica se organiza, portanto, em torno do mal-estar provocado pelo olhar que retorna como mais-de-gozar, dejeto da civilização.

\section{SNOWDEN E OS VAZAMENTOS}

Há também a Internet-Deus que tudo vê, tudo ouve e tudo sabe. Desde junho de 2013 sabemos do sistema de espionagem em massa dos Estados Unidos revelado por Snowden, hoje com 35 anos, que se encontra escondido em lugar desconhecido em seu asilo na Rússia para escapar da justiça americana. Todos somos monitorados 24 horas por dia. Ao frequentar a internet, o Google, as redes sociais (Facebook, Twitter, Instagram, etc), Whatsapp, enviar e receber e-mails, usar os localizadores de rota como Waze, Google Maps todos seus dados pessoais, e os nomes de seus parentes, de seus amigos, seus gostos sexuais, de roupa, de consumo em geral, sua preferência política, o uso de seu tempo, tudo está devidamente cadastrado para todos os fins possíveis: políticos, religiosos e de consumo e marketing.

Essa questão merece ser debatida. Conforme disse Snowden em entrevista para a televisão brasileira em junho de 2014 (TV Globo, programa "Fantástico") "esse debate não é só sobre a privacidade, mas sobre a essência da liberdade. Se vigiarmos cada homem desde que nasce até a hora em que morre podemos dizer que eles são livres?" E ele acrescenta algo que coloca em cena a relação de subserviência do ego para com a tirania do superego - relação essa utilizada pela sociedade escópica da era digital: 'É perigoso pois mudamos nosso comportamento quando sabemos que estamos sendo vigiados". Essa tática usada no panoptismo da prisão faz os detentos terem um bom comportamento, ou seja, para não serem punidos - o que é ampliado em grande escala na sociedade disciplinar descrita por Foucault e é hoje já utilizada na China para determinar o comportamento dos "cidadãos de bem". Em 2017, foi revelado pelo The New York Times que a NSA (National Security Agency dos EUA) está coletando imagens de nada mais nada menos do que TODOS para constituir um banco de dados das imagens dos rostos para reconhecimento imediato por robôs. "É como se os EUA estivessem contratando detetives particulares para seguir todo o mundo", comentou Snowden no programa citado. O pretexto alegado para essa coleta de dados de combater o terrorismo é desmentido por Snowden em entrevista de agosto de 2018: "a manipulação das eleições de outros países, especialmente os países vizinhos, está dentre os trabalhos realizados pela agência de inteligência. Os 
grupos terroristas não são vistos como uma grande ameaça (para os EUA). Esses programas de monitoramento não são de segurança pública, eles são hackers."

É a sociedade escópica em sua função de espionagem. Do alto do panóptico que nem se sabe onde está - há Um espião que não se sabe quem é invisível e todos somos espiados.

\section{HOJE No BRASIL}

O ódio se instalou nos lares, nos bares e nos mares de todas as praias do Brasil. O terror de hoje não é o mesmo da época da ditadura militar (64-85). A técnica eleitoral (importada para o Brasil a comando de Steve Banon) via internet não tem ética nem pudor. $O$ terrorismo virtual fez o improvável acontecer: a platitude de ideias escassas divulgadas e repetidas à exaustação, próprias da propaganda fascista, a avalanche de fake news, a falta de dialetização e a instalação de uma razão ao mesmo tempo messiânica e paranoica fez ganhar uma eleição. E o candidato da extremadireita virou o Grande Youtuber, como o Grande Irmão do romance 1984 de Gerge Orwell. O que se anunciou na "campanha" arrisca de virar forma de governo em nosso admirável mundo novo. E assim provocar o abominável e inédito linchamento virtual. Para acabar com a reputação de alguém não precisa de argumentos, basta xingamento.

A primeira lista de malditos do regime no Brasil já saiu repleta de artistas e até de psicanalistas a serem boicotados. Não vai ser necessária uma custosa censura de Estado como na época da ditadura militar, pois teremos a "censura cidadã" e um exército virtual e anônimo de pessoas e robôs eletrônicos assim como pessoas robotizadas destruindo a reputação de alguém e incitando sua destruição física (como as ameaças sofridas pela jornalista Patrícia de Campos Mello da Folha de São Paulo autora da matéria sobre o caixa 2 da "campanha" de Bolsonaro). Os "homens de bem" e os tenentes de Deus serão os novos defensores da moral, dos bons costumes e do policiamento. E sua moral incita a violência e seu discurso legitima a perseguição aos que pensam distintamente pela massa anônima de fanáticos religiosos. Uma professora universitária que escreve a favor da legalização do aborto teve que deixar o país devido a ameaças contra sua vida.

O novo presidente youtuber poderá assim se dirigir diretamente a cada cidadão, um a um (como o fez ao estudante João Luis para que filme sua professora 
durante a aula). Estará presente nos lares pelos celu-lares desde um "Bom dia" até um "Boa noite" a cada um em sua intimidade. E assim ocupar o lugar topológico de das Ding, a exterioridade íntima, a extimidade. O celular é a nova cela de prisão e o novo lar: a nova cela do sujeito e o novo lar do presidente. Nessa nova cela virtual, cada um está cada vez mais preso quanto mais exerce sua suposta liberdade. Quanto mais você surfa mais você se afoga.

O estrategista da campanha do presidenciável Bolsonaro, Ariek Wierson, desvelou, antes mesmo da apuração dos votos, a intenção de distribuir celulares de graça para a população. Trata-se em suma de criminalizar os sem teto e os sem terra e favorecer os sem celular. É um projeto comandado pelo discurso capitalista de instalar um Estado paranoico com uma moral dos costumes a ser vigiada e punida num governo ultraliberal.

Eis uma arma do Estado paranoico que permite desde a eleição de presidentes da República como do EUA e do Brasil até a relação direta do líder não com a massa, mas com cada um individualmente em sua própria intimidade fazendo um curtocircuito todas as instituições democráticas para falar diretamente com o povo. É uma nova forma de fascismo mantendo a fachada de democracia.

\section{China Hoje é o Mundo Amanhã}

A sociedade escópica digital terá na China em 2020 as funções não só de controle e vigilância, mas também de punição e premiação dos 1,4 bilhões de cidadãos chineses que serão colocadas em prática pelo governo. Como? Implantando um sistema de monitoramento, ou melhor "ranking social", em que todos serão avaliados (como no Uber) em função de seus comportamentos, compras, hábitos e ideias. Suas fontes são os dados recolhidos do comportamento digital pela internet: redes sociais, dados pessoais, sexuais, bancários, acessos de sites, vídeos, youtubers, jornais, rotas diárias a pé, de carro ou transportes públicos e viagens detectadas pelos aplicativos de mapeamento, etc. você quer comprar uma calça na internet: aí você entra em vários sites e não encontra nenhum e vai fazer outra coisa. Na próxima vez que você abrir seu celular está lá a calça correndo atrás de você. $\mathrm{Na}$ China os dados são também recolhidos pelas 600 milhões de câmeras com inteligência artificial espalhadas em todo o país. Um Argus de quase um bilhão de olhos. A avaliação e a posição em que cada um se encontra no ranking social 
(estabelecido segundo os critérios do governo) serão públicos e cada um poderá saber qual é a avaliação de seu parente, de seu vizinho, de seu amigo e de seu inimigo. Assim como no episódio da série Black Mirror, todos os cidadãos saberão tudo de todos. E cria-se um consenso artificial e o desejo de receber sempre uma melhor avaliação desse supereu personificado no sistema que é ao mesmo tempo invisível e anônimo. Mas transforma cada cidadão em um vigilante de seu semelhante. Pois antes mesmo de você conhecer alguém você terá a avaliação dele a sua disposição na internet. E quem sabe no futuro poderá também dar uma "curtida" (um like) em cada um de seus semelhantes. "A pontuação final do ranking poderá influenciar em diferentes aspectos como seleção para uma vaga de trabalho, inscrição em uma determinada escola ou a permissão para assinar um empréstimo no banco" (Redação Galileu. 19/7/2018). Haverá também premiações para aqueles que têm "hábitos corretos" como comprar apenas produtos de origem chinesa.

Estamos na era do ideal da transparência total sem direito algum de privacidade - era do sonho totalitário do controle de tudo e de todos. Assim o governo tomará o lugar mítico de Deus onividente e onipresente que enxerga cada um no âmago de sua vida privada. O panoptismo entra em todos os corações e mentes.

\section{Os Softidiots e a Psicometria Digital}

A armadilha panóptica digital torna a todos softidiots - os idiotas do software. Estamos presos a uma grande rede mundial virtual e digital de manipulação de dados, informação, espionagem e que entrou na política de forma decisiva na votação do Brexit, no Reino Unido, (promovendo sua retirada da Comunidade Europeia) assim como a eleição de Trump e de Bolsonaro. A enxurrada de Fake News, de ataques aos opositores, de calúnias, slogans, memes, encontrando alvos certos e personalizados de propaganda são modalidades da tática para promover o ignoródio.

Com Freud tivemos a teoria da psicologia das massas, com Lacan a teoria dos discursos no campo do gozo para dar conta cada um em sua época ao mal-estar na civilização. Hoje estamos diante de uma nova ordem mundial e temos que ver em que a psicanálise pode nos ajudar para analisar e combater esse ataque cibernético inumano. Por um lado, um ataque sem tréguas do ultra-neoliberalismo do discurso capitalista promovendo o concentracionismo e a mentalidade rentista e individualista que induz a um onanismo consumista que não tem barreiras nem fim a não ser a 
falência, a inadimplência, as dívidas, a pobreza e o suicídio. E do outro lado a indústria da (des) informação digital, o bombardeamento de produtos que são impostos como necessários e a lavagem cerebral para nos transformar em softidiots.

Já se fala em era da pós-verdade, em que memes e slogans são mais importantes do que fatos reais da era da infocalipse - apocalipse informática. Nossas impressões digitais não estão mais nos dedos e sim nos dados digitais. Todos os frequentadores da internet têm suas impressões digitais mapeadas através das curtidas das redes sociais, dos dados pessoais, do gosto pessoal - se você pesquisa o preço de uma calça ela passa a andar atrás de você - gosto sexual, posição política, crença religiosa. Você é espionado 24 horas por dia e a internet te conhece mais do que as pessoas mais próximas a você. Com todos esses dados será que a internet tem um Inconsciente? Os algoritmos e sua combinação são o equivalente ao consciente.

A psicometria digital que é estudada em uma disciplina extraída da formação militar se chama: Op-psi - operação psicológica e que tem até o grau de neurose como critério para sabe que tipo de mensagem enviar para você, como os usados pela Cambridge Analytica, empresa que promoveu a campanha digital de Trump, cujo diretor era o Steve Banon que esteve na campanha de Bolsonaro.

O cruzamento de dados de cada um é estudado por robots a partir de 5 critérios chamado OCEAN: openness (abertura), conscientiousness (conscienteização), extraversion (extroversão), agreeableness (amabilidade), neuroticism (neurose) aplicado a cada eleitor formando grupos variados combinando os outros fatores pessoais já citados. Assim eles sabem exatamente que tipo de mensagem enviar a quem para conquistar seu voto. É o chamado behavior microtargeting. (fonte: Documentário de Thomas Huchon, 2DF/Arte, 2018). E assim somos todos mapeados e alvos personalizados prontinhos para votarmos no boi e irmos todos para 0 matadouro.

\section{A Psicologia das Massas na Era Digital}

$\mathrm{Na}$ era do panoptismo digital da sociedade escópica não se precisa mais propriamente de um líder para incarnar as ideias, ideias que constituem um conjunto humano como grupo ou massa. E talvez nem mesmo de um significante mestre com 
o qual todos se identificam para constituir a Unidade como descrito por Freud em seu texto "Psicologia das massas e análise do eu".

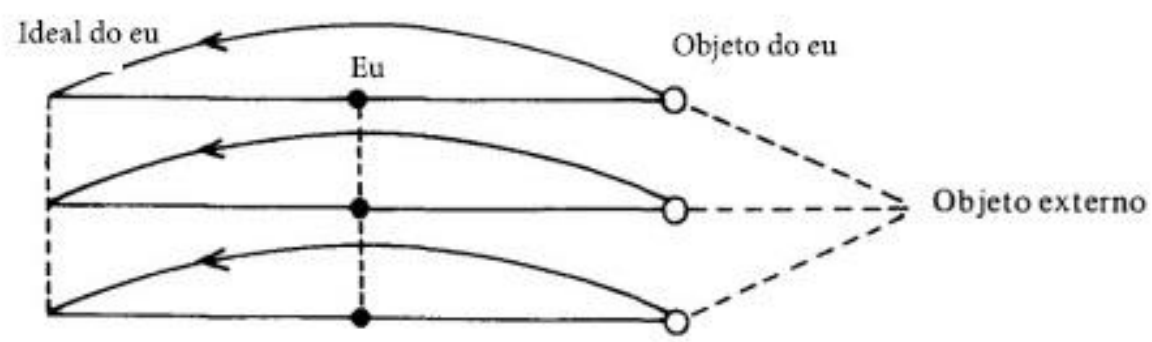

Esquema de Freud

Fonte: Lacan. Seminário, livro 11 (1964/1989, p. 257).

No esquema freudiano o líder está no lugar de ldeal do eu - as linhas mostram como cada sujeito introjeta o "objeto externo" que é o líder e o coloca no lugar de seu ideal do eu. Eis porque cada indivíduo dirige seu amor a ele confundindo-o com a instância paterna internalizada, remanescente do narcisismo e do complexo de Édipo, é a instância psíquica do representante simbólico do amor parental que alimenta o narcisismo. O ideal do eu é uma instância que funciona como um lugar - ocupado por algumas pessoas - de onde o sujeito se vê como digno de amor. Ao situar o líder nesse lugar, o sujeito não só o ama como a um pai, como também espera seu amor. Às vezes só o fato de amar o líder é suficiente para se sentir amado por ele devido à estrutura de reciprocidade intrínseca do amor (amar e ser amado). Assim o líder chamado por Freud em seu esquema de "objeto externo" vem ocupar o lugar de Ideal do eu, como a encarnação do significante-mestre (S1), que é na verdade um ideal do Outro $[\mathrm{I}(\mathrm{A})]$.

Como Lacan nos indica, há uma confusão entre o significante ideal e o objeto a. É nisso que reside o poder hipnótico do líder, pois como no hipnotizador, reside nesse o objeto a que está em jogo sob o ideal do eu que ele representa para cada sujeito da massa. Trata-se, no caso o objeto escópico, o olhar, como objeto pulsional, representante do supereu.

$\mathrm{Na}$ era do panoptismo digital todo o dispositivo completo de espionagem de dados, a multiplicação das câmeras, o sistema contínuo de avaliação e notas para em breve ser cada sujeito se colocado num lugar no "ranking social" é um mecanismo 
para fazer existir o olhar, como instância superegóica na extimidade do sujeito, ou seja, em sua exterioridade íntima. Isso se torna mais ainda evidente quando o líder vem se dirigir através de vídeo para o cidadão que está na sua cama acordando e ligando seu celular. Assim na nova psicologia das massas é o objeto a, como mais de gozar, que se presentifica um a um, não sendo mais necessário nem mesmo um pensamento, uma reflexão, um sistema de valores ou uma filosofia para constituir o grupo. Isso não quer dizer que não seja utilizado para impor um pensamento único. Mas a estrutura da massa prescinde da identificação ao líder que tem por base o Ideal do eu, pois o líder vem no lugar da causa de desejo, como olhar e voz, e como supereu.

A mola fundamental da operação analítica é manter a distância entre o ideal e o objeto a, para poder esvaziar de gozo esse lugar do ideal do eu e fazer cair o objeto a, para que o sujeito o localize como causa de seu desejo, ou seja como uma formação sua e não do Outro. A psicanálise nos mostra que esse olhar estruturalmente não tem substância, é um furo; o Outro é cego e seu lugar um deserto de gozo. Para "contrariar o desejo do tirano", que Lacan eleva à condição de máxima da psicanálise é preciso saber que o Outro não é Um e que para ele, também, o olhar é um objeto perdido e, sem o objeto, o Outro não existe. Barrar o olhar do Outro é torná-lo inconsistente.

Uma psicanálise não suprime inteiramente o olhar correlatado ao dar-a-ver do sujeito, mesmo quando ele encontra a inconsistência do Outro. Mas o sujeito, depois de uma análise, percebe seu caráter de semblante de ser, o que o esvazia de sua virulência mortífera.

Termino meu livro "Um olhar a mais" propondo pensarmos uma ética do olhar que é tributária do objeto causa do desejo. Ela é a que promove o desejo que agalmatiza os objetos do mundo empírico escopizando-os para o sujeito, pois ele vê muitos objetos mas escopiza somente aqueles de seu desejo. A ética do olhar é a que corresponde ao desejo de saber que não visa o gozo escópico da completude, mas que afirma que a falta de saber é constituinte do desejo que a anima. Um desejo de saber que possa se sobrepor à paixão da ignorância. 


\title{
Paranoia of the Digital Age Softidiots AND BIGBROTHERIZATION
}

\begin{abstract}
This essay is an analysis of the paranoiac state structure in the digital era based on the concepts of scopic society (Quinet), gaze as objet (a) (Lacan) and group psychology (Freud). The scopic drive along with its correlated jouissance - to see and to be seen - is the basis for the Bentham panopticon model of the disciplinary society xdescribed by Michel Foucault. This model reachd its zenith in our digital era. We study the application of this model in politics with the bigbrotherization strategy aiming to desubjectivate and manipulate individuals and produce softidiots. This is the current tendancy in many countries such as Brazil and China, albeit with different results.
\end{abstract}

KEYWORDS: Paranoia; Panopticon; Bigbrotherization; Psychoanalysis; Scopic Pulsion 


\section{Paranoïa Des Masses De L'Ère Numérique, Les Softidiots ET LA BIGROTHÉRISATION}

\section{RÉSUMÉ}

Ce travail est un essai sur la structure de l'état paranoïaque à l'ère numérique à partir des concepts de la société scopique (Quinet), regard comme objet (a) (Lacan) et de la psychologie des masses (Freud). La pulsion scopique à partir de la jouissance de voir-être-vu donne la base au modèle panoptique de Bentham de la société disciplinaire de surveillance monitorisée développée par Michel Foucault.ce modèle a atteint son zenith à l' ]

ère numérique. ous étudions son utilisation dans la politique avec la stratégie de bigbrotherisation qui a pour du objectif la manipulation désubjectivante et la formation de softidiots. Voilà la tendance que nous trouvons particulièrement dans la conjoncture actuelle dans plusieurs pays comme le Brésil et la Chine, malgré leur différences.

MотS-ÉcLÉS: Paranoïa; Panoptique; Bigbrotherization; Psychanalyse; Pulsion Scopique 
(C) 2019 Psicanálise \& Barroco em revista

http://www.seer.unirio.br/index.php/psicanalise-barroco/index revista@psicanaliseebarroco.pro.br

Programa de Pós-Graduação em Memória Social — UNIRIO Memória, Subjetividade e Criação www.memoriasocial.pro.br/proposta-area.php 